\title{
A new method for the production of low-fat Cheddar cheese ${ }^{1}$
}

\author{
Irma Amelia, ${ }^{*}$ MaryAnne Drake,† Brandon Nelson, $\ddagger$ and David M. Barbano*2 \\ *Northeast Dairy Foods Research Center, Department of Food Science, Cornell University, Ithaca, NY 14853 \\ †Southeast Dairy Foods Research Center, Department of Food Science, North Carolina State University, Raleigh 27695 \\ ‡Daisy Brand LLC, Garland, TX 75041
}

\begin{abstract}
Our objective was to develop an alternative process to produce low-fat Cheddar cheese (LFCC) by combining reduced-fat Cheddar cheese (RFCC) made by a fat-removal process with micellar casein concentrate (MCC) to try to achieve the texture and flavor characteristics of full-fat Cheddar cheese (FFCC). The production of LFCC was replicated 3 times. The MCC was produced by ultrafiltration of skim milk, followed by 3 stages of microfiltration, and the final MCC was spray dried. The LFCC was formulated to achieve $6 \%$ fat, $28 \%$ protein, and $1.2 \%$ salt by a combination of RFCC, MCC powder, salt, and water. The $6 \%$ fat target was selected to comply with the FDA standard for a low-fat label claim. The $\mathrm{pH}$ of the LFCC mixture was adjusted to 5.3 by lactic acid. Rennet was added to the LFCC mixture, followed by pressing and packaging. Chemical and sensory data were analyzed by ANOVA using the Proc GLM of SAS to determine if any differences in chemical composition and sensory properties were present among different cheeses. Descriptive sensory scores were used to construct a principal component analysis biplot to visualize flavor profile differences among cheeses. The LFCC had $83 \%$ less fat, $32 \%$ less sodium, and higher protein and moisture content than FFCC. When the cheese texture was evaluated in the context of a filled-gel model consisting of matrix and filler $(100 \%$ minus percentage of matrix) the LFCC had lower filler volume than FFCC, yet the LFCC had a softer texture than FFCC. The LFCC contained some of the original FFCC cheese matrix that had been disrupted by the fat-removal process, and this original FFCC matrix was embedded in the new LFCC matrix formed by the action of rennet on casein from the continuous phase of hydrated MCC. Thus, the texture of the LFCC was desirable and was softer than the FFCC it was made
\end{abstract}

\footnotetext{
Received December 31, 2012.

Accepted April 1, 2013.

${ }^{1}$ Use of names, names of ingredients, and identification of specific models of equipment is for scientific clarity and does not constitute any endorsement of product by authors, Cornell University, or the Northeast Dairy Foods Research Center.

${ }^{2}$ Corresponding author: dmb37@cornell.edu
}

from, whereas commercial RFCC (50 and $75 \%$ fat reduction) were firmer than the FFCC. The sulfur flavor in LFCC was closer to FFCC than commercial RFCC. The LFCC had bitter and grape-tortilla off-flavors that came from the dried MCC ingredient. The commercial RFCC and LFCC made in this study were missing the typical aged Cheddar character (catty, nutty, fruity, brothy, milk fat flavors) found in aged FFCC. Future work to improve the flavor of LFCC made by the process described in this study should include the addition of a flavoring ingredient (e.g., enzyme-modified cheese) to enhance the aged Cheddar flavors and mask undesirable flavors.

Key words: cheese, low fat, micellar casein concentrate

\section{INTRODUCTION}

With a rising prevalence of obesity in the United States, individuals are advised to make significant changes in their lifestyle, which includes healthier eating habits. In the Dietary Guidelines for Americans (USDA CNPP, 2010), the recommended fat intake for adults should be less than $35 \%$ of total caloric intake. This translates to a maximum of $78 \mathrm{~g}$ of fat per day in a 2,000 calorie diet. Although Cheddar cheese is considered a nutrient-dense food providing high protein and calcium to the human diet, it contributes significantly to dietary fat intake. Cheddar cheese contains $9 \mathrm{~g}$ of fat per each $28 \mathrm{-g}$ serving. Eating smaller amounts of full-fat foods, or substituting a reduced-fat version, is a strategy that can be used to achieve dietary fat reduction. To help consumers meet the dietary guidelines, the cheese industry strives to provide a healthier Cheddar cheese option that has reduced fat. The FDA regulation mandates that food products claiming to be low fat must not contain more than $3 \mathrm{~g}$ of fat per reference amount (50 g), whereas reduced fat labeling can be used for food that contains $25 \%$ less fat than the regular version (FDA-DHHS, 2002).

Is it easy to make a good quality reduced-fat Cheddar cheese (RFCC)? It's technically challenging to produce RFCC with flavor and texture comparable to full-fat Cheddar cheese (FFCC). Extensive reviews 
about reduced- and low-fat cheese are available (Drake and Swanson, 1995; Mistry, 2001; Banks, 2004; Johnson et al. 2009), all of which reported poor flavor and texture of reduced- and low-fat cheeses. Some of the flavor defects mentioned included meaty, brothy, burnt, bitterness, low flavor intensity and milk fat flavor. In terms of texture, RFCC is perceived to be firmer, rubbery, waxier, more brittle, as well as less sticky and cohesive than FFCC. Cheeses of 6, 16, and 33\% fat were tested at $0.5,3,6$, and 9 mo of aging by Rogers et al. (2010) and they reported that low-fat cheeses were differentiated from full-fat cheeses by being more springy and firm and this difference widened as the cheeses aged. In addition, they reported that full-fat cheeses broke down more during chewing than the lower-fat cheeses and the degree of breakdown increased with aging. The production of RFCC with up to $75 \%$ fat reduction has found some success and is commercially available (Schepers, 2005). However, we did not find any low-fat Cheddar cheese (LFCC; which had $>82 \%$ fat reduction) in the market place. This is because the larger the fat reduction, the more severe the flavor and texture defects in the cheese. This principle was clearly shown by Childs and Drake (2009) through choice-based conjoint analysis and consumer acceptance testing that show flavor followed by texture of cheese are important attributes that determine consumption, and consumer acceptance of a commercial RFCC ( $75 \%$ reduced fat) dropped dramatically due to profound differences in flavor and texture when compared with regular FFCC.

The effect of fat reduction on flavor development in Cheddar cheese was studied by Drake et al. (2010). It was found that flavor differences between FFCC and LFCC were not apparent at 2 wk of ripening, but by 9 mo of ripening pronounced flavor differences were observed. The FFCC had higher brothy, sulfur, and milk fat flavor than LFCC at 9 mo of ripening. In addition, LFCC had higher bitterness than FFCC and developed a burnt rosy flavor that was not detected in FFCC. Likewise, instrumental analysis showed similar key odorants in LFCC and FFCC at 2 wk of ripening, however the key odorants in FFCC and LFCC showed more differences at 9 mo of ripening. It was also reported by Drake et al. (2010) that FFCC and LFCC were composed of identical volatile compounds, but in different concentrations. These differences might be related to differences in microbiological and proteolytic activity during aging that were caused by the difference in fat level and the balance of compounds in the aqueous phase of the cheese. Fenelon et al. (2000a) showed that the rate of growth of nonstarter lactic acid bacteria decreased with lower fat content in cheese, but found a small effect on the starter population throughout 225-d ripening among cheeses with various fat contents. They found lower primary proteolysis in lower-fat cheeses, as reflected in $\mathrm{pH} 4.6$ water-soluble nitrogen as a percentage of total nitrogen, but no differences in secondary proteolysis in cheeses with different fat contents, as reflected in AA nitrogen as a percentage of total nitrogen. Another challenge in the flavor of RFCC and LFCC is the fact that volatile compounds have different threshold levels depending on the environment they are in. Hydrophobic compounds have a higher threshold level in FFCC (less polar) than RFCC or LFCC (more polar) because they are more soluble in the former environment, preventing their release in the headspace (Leksrisompong et al., 2010; Kim et al., 2011).

The effect of fat reduction on the texture of Cheddar cheese can be explained in the context of the filled-gel model, described by Visser (1991). Cheese consists of gel matrix and filler; $\mathrm{CN}$ and bound mineral in a cheese serves as the gel matrix, whereas the rest of the constituents are filler. The CN gel matrix determines the solid nature of cheese. The higher the matrix volume, the firmer is the cheese. The reduction of fat in cheese concomitantly increases the protein content in cheese (Bryant et al. 1995; Fenelon et al. 2000a,b; Guinee et al., 2000; Drake et al. 2010), causing an increase in matrix and reduction in filler. This explains the high firmness in reduced-fat cheese. The microstructure difference between FFCC and LFCC produced by removing fat from milk before cheese making is also evident from the scanning electron micrograph, showing a more compact protein matrix per given volume and less open space occupied by the milk fat globules in LFCC than FFCC (Emmons et al., 1980; Bryant et al. 1995).

Many approaches have been investigated to overcome defects in RFCC and LFCC. One approach investigated was use of adjunct culture to improve the flavor in RFCC and LFCC. Fenelon et al. (2002) demonstrated the use of Lactobacillus helveticus as adjunct culture, in combination with Leuconostoc cremoris, Lactococcus lactis var. diacetylactis and Streptococcus thermophilus to produce RFCC (50\% fat reduction), had a higher preference score than the RFCC without adjunct culture. The RFCC with these adjunct cultures showed a higher degree of peptide hydrolysis and greater free AA concentration. However, even the most acceptable RFCC in the study by Fenelon et al. (2002) was still described as having a different flavor profile than typical FFCC, as well as a burnt off-flavor. To improve the texture of RFCC and LFCC, cheese makers try to maximize moisture retention (i.e., increase filler volume) in the curd. This can be done by modifying the make procedure, such as increasing milk pasteurization temperature (Guinee et al., 1998), lowering scald temperature (Banks et al., 1989), washing curd with $22^{\circ} \mathrm{C}$ water (Johnson and Chen, 1995), milling curd at 
higher pH (Guinee et al., 1998), or by incorporating denatured whey protein (Lo and Bastian, 1998), hydrocolloids (Konuklar et al., 2004), or exopolysaccharideproducing cheese starter cultures (Dabour et al., 2006). Some of these techniques improved the quality RFCC; however, none of them has been successfully applied to produce commercially acceptable LFCC.

Nelson and Barbano (2004) introduced a nonconventional method for producing RFCC by removing fat from an aged FFCC in which the typical Cheddar-characteristic flavors had already developed. This method was able to remove as much as $53 \%$ of the fat and avoid flavor and texture problems common in RFCC made by the conventional process. The RFCC made by the fat-removal process was softer and creamier than the original FFCC (Nelson and Barbano, 2004) and also maintained the same flavor intensity as the FFCC, according to consumer testing and a similar attribute profile by trained panelists (Carunchia Whetstine et al., 2006). The similarity of flavor profiles in FFCC and RFCC produced by this method confirmed previous findings that purported that the taste-active compounds in Cheddar cheese reside in the water-soluble extracts (McGugan et al., 1979; Aston and Creamer, 1986; Andersen et al., 2010). Whereas the filler volume was increased in the cheese produced by the fat-removal process, the major improvement in texture was caused by the change in the matrix structure occurring via the manufacturing process (Nelson and Barbano, 2004).

A different approach for making LFCC would be to build LFCC from its components and avoid the cheeseaging process. The main components of the nonfat portion of the Cheddar cheese are protein (mainly $\mathrm{CN}$ ), water, and minerals. Micellar CN concentrate (MCC), which is a new dairy ingredient made by microfiltration of skim milk, consists of primarily $\mathrm{CN}$ micelles, water (before being spray-dried), and minerals. In other words, hydrated MCC has a similar composition to the fat-free portion of cheese. An RFCC produced by the fat-removal process can be made into LFCC by combining it with MCC to achieve the target fat of $3 \mathrm{~g}$ per each 50 -g reference amount or $1.7 \mathrm{~g}$ per each 28 -g serving. The objective of our study was to develop an alternative process to produce LFCC, which does not require aging or flavor development, by combining RFCC made by a fat-removal process with MCC to try to achieve the texture and flavor characteristics of FFCC.

\section{MATERIALS AND METHODS}

\section{Experimental Design and Statistical Analysis}

Three different lots of 12- to 14-mo-old aged FFCC, weighing approximately $2.7 \mathrm{~kg}$, was obtained from a commercial manufacturer. Half of the FFCC was used to produce RFCC using a fat-removal process (Nelson and Barbano, 2004), whereas the remainder of FFCC was stored for chemical and sensory analyses. In making LFCC, the RFCC was combined with hydrated MCC powder to achieve a fat content of $6 \%$, or $3 \mathrm{~g}$ of fat per $50 \mathrm{~g}$ of the product, to comply with the FDA standard for a low fat label claim (FDA-DHHS, 2002). The production of LFCC was replicated 3 times starting with different lots of FFCC that were used to make RFCC. The sensory and chemical analyses were conducted on LFCC, as well as on the corresponding FFCC, commercial 50\% RFCC, and commercial $75 \%$ RFCC. The $50 \%$ RFCC and $75 \%$ RFCC were obtained from the same manufacturer as the FFCC, and from 3 different lot numbers randomly assigned as replicate 1 , 2 , or 3 . The LFCC was stored at $4^{\circ} \mathrm{C}$ for 4 mo before sensory analysis to reflect some time of storage of the LFCC that would occur during the distribution and marketing process.

Chemical and sensory data were analyzed by ANOVA using the Proc GLM procedures of SAS (SAS version 8.02; SAS Institute Inc., Cary, NC) to determine if significant differences (i.e., $P<0.05$ ) in chemical composition or sensory properties existed among treatments (FFCC, $50 \%$ RFCC, $75 \%$ RFCC, LFCC). The GLM model for chemical analyses was dependent variable $=$ treatment + replicate + error. The GLM model for analysis of descriptive sensory data was dependent variable $=$ treatment + replicate + panelist + treatment $\times$ replicate + treatments $\times$ panelist + replicate $\times$ panelist + error. Any main effects and interactions that were not significant (i.e., $P>0.05$ ) were removed in a stepwise order starting with the term with the lowest type III sum of squares. To visualize any differences among cheese of different treatments with respect to sensory attributes, the scores from descriptive sensory analyses were used to construct a principal component analysis (PCA) biplot using XLStat (Addinsoft, New York, NY).

\section{Production of MCC Powder}

The MCC powder was produced by spray-drying of liquid 95\% serum protein-reduced MCC (approximately $10 \%$ protein). Liquid MCC was produced by UF of skim milk, followed by 3 stages of microfiltration (MF). On $\mathrm{d} 1$, the incoming raw milk was pasteurized at $72^{\circ} \mathrm{C}$ for $16 \mathrm{~s}$ with a plate heat exchanger (model 080-S, AGC Engineering, Manassas, VA), and then separated at $49^{\circ} \mathrm{C}$ using a cream separator (model 619, DeLaval Co., Chicago, IL). The pasteurized skim milk was ultrafiltered $\left(50^{\circ} \mathrm{C}\right)$ using a polyethersulfone spiral-wound UF membrane with a nominal pore size of 10,000 Da (model 
3838, GEA Niro Inc., Hudson,WI) in a batch recirculation mode $[2.2 \times$ concentration factor $(\mathbf{C F})]$. The UF retentate inlet pressure was $276 \mathrm{kPa}$ and the retentate outlet pressure was $103 \mathrm{kPa}$. The UF retentate was diluted with cold reverse osmosis (RO) water to reach the original protein content in skim milk and then stored overnight at $4^{\circ} \mathrm{C}$. On d 2, the $\mathrm{RO}$ water-diluted $\mathrm{UF}$ retentate was $\mathrm{MF}$ at $50^{\circ} \mathrm{C}$ using a $0.1-\mu \mathrm{m}$ nominal pore diameter ceramic Membralox graded permeability membrane (model EP1940GL0.1 $\mu$ AGP1020, alumina, Pall Corp., Cortland, NY) with $1.7 \mathrm{~m}^{2}$ of surface area. This MF process was a continuous bleed and feed, and the $\mathrm{CF}$ was set to $3 \times$ with retentate and permeate removal rates of 60 and $120 \mathrm{~L} / \mathrm{h}$, respectively, which produced a permeate flux of $71 \mathrm{~L} / \mathrm{m}^{2}$ per hour. On $\mathrm{d}$ 3, two additional MF stages were performed as diafiltration, where the retentate from the previous stage was diluted back to its original weight with $\mathrm{RO}$ water and used as the feed intake. Diafiltration was done to achieve a more complete removal NPN and serum protein. Microfiltration stages 2 and 3 were a continuous bleed and feed with a CF of $3 \times$. The MF stage 3 retentate was further concentrated to approximately $10 \%$ protein and stored at $4^{\circ} \mathrm{C}$ before being spray-dried the following day. A Niro spray dryer model 1 with an FU11 atomizer (Niro Atomizer Inc., Columbia, MD) was used with a rotating speed of 23,000 rpm and a feed rate of $14 \mathrm{~kg} / \mathrm{h}$. The inlet and outlet temperature of the spray dryer was 200 and $95^{\circ} \mathrm{C}$, respectively. It took approximately $3 \mathrm{~h}$ to dry $37 \mathrm{~kg}$ of feed material. The final temperature of the powder was about 30 to $35^{\circ} \mathrm{C}$. The powder from the first $10 \mathrm{~min}$ of spray drying was discarded. The remainder of the powder was mixed and packaged in a mylar resealable bags (Sorbent Systems, Los Angeles CA).

\section{Production of RFCC}

The RFCC was made using the fat-removal process of Nelson and Barbano (2004). The shredded FFCC cheese was portioned in 250-mL polypropylene Oakridge centrifuge tubes (approximately $60 \mathrm{~g}$ per tube) with screw top caps (Kendro Laboratory Products, Newtown, CT) and held at $4^{\circ} \mathrm{C}$. The tubes were tempered in a shaking water bath (model 236 Versa-Bath S, Fisher Scientific, Pittsburgh, PA) set at $35^{\circ} \mathrm{C}$ and $40 \mathrm{rpm}$ for approximately $1 \mathrm{~h}$ to achieve a cheese temperature of $35^{\circ} \mathrm{C}$. The tubes were immediately placed into a $35^{\circ} \mathrm{C}$ Sorvall RC2-B Superspeed centrifuge with a GSA rotor (Sorval Inc., Newtown, CT) operated at 23,500 $\times g$ for $5 \mathrm{~min}$. The liquid fat was decanted from each tube. The collective cheese residues were mixed in a food processor with a Sabatier blade attachment (Kitchen Aid, St. Joseph, MI), followed by pressing them by hand in a cheese mold and vacuum packaging (Multivac AGW, Koch, Inc., Kansas City, MO). The RFCC was stored at $4^{\circ} \mathrm{C}$ until needed for the production of LFCC and composition analysis.

\section{Production of LFCC}

The RFCC and MCC powder were analyzed for composition and that data was used for the formulation of the LFCC to achieve $6 \%$ fat, $28 \%$ protein, and $1.2 \%$ salt by combination of RFCC, MCC powder, salt, and RO water (Table 1). The MCC powder was hydrated gradually by adding it to $65^{\circ} \mathrm{C} \mathrm{RO}$ water with continuous mixing using an overhead stirrer (Model NQ47, Fisher Scientific). Salt was added to the mixture, followed by continuous mixing for $40 \mathrm{~min}$ to ensure proper hydration. Throughout the mixing process, the temperature of the system was maintained at $60^{\circ} \mathrm{C}$ in a water bath to aid in the hydration of MCC powder. The amount of moisture lost due to evaporation during the mixing process, as calculated using mass balance, was added back to the mixture. The mixture was put in a food processor (Kitchen Aid) with a Sabatier blade attachment and mixed to achieve homogenous mixture with no lumps (approximately $10 \mathrm{~s}$ of continuous mixing). The preshredded RFCC was added gradually into the hydrated MCC mixture and mixed intermittently in the food processor. After all RFCC was added, the mixing was standardized across the 3 replicates by using thirty 1-s mixing pulses followed by 1 min of continuous mixing. The $\mathrm{pH}$ of the mixture was measured at $37^{\circ} \mathrm{C}$ using a Xerolyt combination electrode (model HA405, Mettler Toledo, Colombus, OH) and an Accumet pH meter (model 925, Fisher Scientific, Springfield, NJ). DL-Lactic acid, $85 \%$ wt/wt USP/FCC (Fisher Scientific), was added drop-by-drop, followed by mixing intermittently in the food processor, until the $\mathrm{pH}$ of the LFCC mix was 5.3. The LFCC mix was weighed to calculate the amount of rennet (Chy-max extra, double strength, activity: 600 International Milk Clotting Units/mL, Chr. Hansen Inc., Milwaukee, WI) needed. The undiluted rennet addition rate was 0.00031 $\mathrm{mL} / \mathrm{g}$ of protein derived from the MCC. The rennet was diluted to 1:20 ratio with water before being added to the LFCC mix (at 34 to $36^{\circ} \mathrm{C}$ ) and blended in uniformly using a spatula. Approximately $1 \mathrm{~mL}$ of diluted rennet was needed for $1 \mathrm{~kg}$ of the LFCC mix. Following the incorporation of rennet, the LFCC mix was packed by hand into a cheese mold. The LFCC mix plus rennet was held at ambient temperature $\left(21^{\circ} \mathrm{C}\right)$ for $30 \mathrm{~min}$ to allow reaction of the rennet and MCC. At the end of 30 min, a small amount of whey drainage, approximately $1.82 \%$ of the total cheese weight, was observed. The LFCC was removed from the mold and vacuum packed 
Table 1. Formula to produce low-fat Cheddar cheese (LFCC) for replicate 1, 2, and 3 and $\mathrm{pH}$ adjustment in LFCC by lactic acid to a target $\mathrm{pH}$ of 5.3

\begin{tabular}{lccrr}
\hline & \multicolumn{3}{c}{ Usage } \\
\cline { 2 - 5 } Ingredient (\%) & Replicate 1 & Replicate 2 & Replicate 3 & Mean \\
\hline Reduced-fat Cheddar cheese (RFCC) & 32.05 & 33.50 & 35.32 & 33.62 \\
Micellar casein concentrate powder & 21.61 & 20.61 & 19.86 & 20.69 \\
Water & 44.83 & 44.82 & 43.68 & 44.44 \\
Salt & 0.51 & 0.45 & 0.30 & 0.42 \\
Lactic acid racemic (85\% wt/wt) & 1.00 & 0.62 & 0.85 & 0.82 \\
Total & 100.00 & 100.00 & 100.00 & 100.00 \\
pH of RFCC & 5.28 & 5.07 & 5.28 & 5.21 \\
pH of LFCC mix before pH adjustment & 5.86 & 5.70 & 5.77 & 5.78 \\
pH of LFCC mix after pH adjustment & 5.25 & 5.28 & 5.28 & 5.27 \\
pH measured after 2 wk of storage & 5.37 & 5.57 & 5.54 & 5.49 \\
\hline
\end{tabular}

(Multivac AGW, Koch Inc.) when the temperature of the cheese was approximately 22 to $25^{\circ} \mathrm{C}$. The temperature of the cheese before vacuum packing was important for the cheese texture. If the temperature was too high, the cheese deformed when vacuum packed, whereas at lower temperatures the cheese did not fuse together and achieve uniform texture. After vacuum packing, the LFCC was held at ambient temperature $\left(21^{\circ} \mathrm{C}\right)$ for $30 \mathrm{~min}$ to allow the structure to close, and then refrigerated at $4^{\circ} \mathrm{C}$.

\section{Powder and Cheese Composition, $\mathrm{pH}$, and Titratable Acidity}

The MCC powder was reconstituted to $10 \%$ solids in $\mathrm{RO}$ water for analyses. The moisture content and total nitrogen was measured in triplicate by forced-air oven drying at $100^{\circ} \mathrm{C}$ for $4 \mathrm{~h}$ (AOAC International, 2000; 33.2.44, method 990.20) and by the Kjeldahl method (AOAC International, 2000; 991.20, method 33.2.11). Total fat was determined in duplicate using ether extraction (AOAC International, 2000; 989.05 method 33.2.26). The $\mathrm{pH}$ was measured by a Xerolyt combination electrode (model HA405; Mettler Toledo) and Accumet pH meter (model 925, Fisher Scientific).

Cheeses were cut into $2.5-\mathrm{cm}$ cubes and ground in a Waring blender (Model 31BL92, Waring Products, Torrington, $\mathrm{CT}$ ) to a uniform particle size of 2 to $3 \mathrm{~mm}$. After thorough mixing, the ground cheese was packed into 2-oz. universal vials (model CPP02, Capitol Vial Inc., Auburn, AL) with no head space and stored at $4^{\circ} \mathrm{C}$ until the day of analysis. Cheese samples were analyzed within a week after the grinding. Moisture was determined (in quadruplicate) by drying a 2 -g portion in a forced-air oven at $100^{\circ} \mathrm{C}$ for $24 \mathrm{~h}$ (AOAC International, $2000 ; 33.2 .44,990.20$ ). Fat in cheese was determined (in triplicate) using a Babcock method (Wehr and Frank, 2004; method number 15.083). Salt content was measured (in duplicate) using the Volhard method (Wehr and Frank, 2004; method number 15.052). Cheese pH was measured using a Xerolyt (model HA405; Mettler Toledo) combination electrode and Accumet $\mathrm{pH}$ meter (model 925, Fisher Scientific). Cheese titratable acidity (TA) was measured as described by Lau et al. (1991).

\section{Sensory Analysis}

Cheddar cheese samples were cut into cubes and placed into lidded 58-mL soufflé cups with 3 -digit codes. Cheese samples were tempered to room temperature $\left(25 \pm 4^{\circ} \mathrm{C}\right)$ before serving. A group of trained panelists ( $\mathrm{n}=8$; 6 females and 2 males, ages 25 to $48 \mathrm{yr}$ ) at North Carolina State University evaluated the cheeses using an established cheese flavor language and a 0 - to 15-point scale consistent with the spectrum method (Meilgaard et al., 1999; Drake et al., 2001, 2010). Each panelist had a minimum of $80 \mathrm{~h}$ of experience with the descriptive profiling of cheeses. Cheese samples from the same replicate were evaluated in the same session; therefore, there were 3 sensory evaluation sessions corresponding to 3 replicates. Each cheese was evaluated in duplicate by each panelist using paper ballots or Compusense Five version 4.8 software (Compusense Inc., Guelph, Ontario, Canada).

\section{Microstructure}

Cheese samples $(0.8 \times 3 \times 4 \mathrm{~mm})$ were mounted to a specimen holder (ALT 118, Gatan Inc., Pleasanton, CA) and frozen by plunging into liquid nitrogen slush. Mounted samples were transferred under vacuum to the cryo-preparation chamber (ALTO 2500, Gatan Inc., Pleasanton, CA) and fractured using a scalpel. After sublimation, at $-80^{\circ} \mathrm{C}$ for 15 min to reveal the fat and protein structure, the temperature was decreased to $-155^{\circ} \mathrm{C}$ and coated with platinum. Sputter coating $(20$ $\mathrm{mA}$ ) was performed twice at 1-min intervals to prevent sample heating. Coated samples were then transferred 
under vacuum to the field emission scanning electron microscope (Supra 40, Carl Zeiss Microscopy, Thornwood, NY). Imaging was performed at $2 \mathrm{kV}$ (about 6 $\mathrm{mm}$ working distance and $30 \mu \mathrm{m}$ aperture) with signals blended 50:50 from the in-lens and Everhart-Thornley detectors. The cheese samples were maintained at $-155^{\circ} \mathrm{C}$ while imaging.

\section{RESULTS AND DISCUSSION}

\section{Production of MCC Powder and RFCC}

An MCC and 50\% RFCC were the main ingredients used to produce LFCC in our study. The MCC powder used in this study contained $2.26 \%$ moisture, $2.39 \%$ fat, and $83.43 \%$ protein on a wet basis. The $\mathrm{pH}$ of reconstituted MCC powder was 7.13 at $21^{\circ} \mathrm{C}$. The composition of hydrated MCC is similar to the fat-free portion of Cheddar cheese, which is primarily $\mathrm{CN}$ micelles, water, and minerals. Thus, MCC is a good candidate for a low-fat ingredient derived from skim milk that can be used to build the structure of a low-fat cheese.

The fat-removal process produced Cheddar cheese with $52.90,52.31 \%$, and $54.30 \%$ reduced fat compared with the original FFCC, for replicate 1, 2, 3, respectively. The mean fat reduction for the 3 replicates was $53.17 \%$ for the RFCC ingredient.

\section{Production of LFCC}

Our target of $6 \%$ fat when formulating the LFCC cheese complied with the FDA regulation for low-fat food labeling (FDA-DHHS, 2002). The $28 \%$ protein and $1.2 \%$ salt targets were based on empirical findings (from our preliminary testing; data not reported) that this composition produced a product that had desirable texture and saltiness perception. With a protein lower than the $28 \%$ protein target, the texture of the LFCC cheese was too soft, whereas achieving a protein higher than the target posed a challenge because the MCC solution (MCC plus RO water) was too viscous to mix properly. The formulation of LFCC for the 3 replicates is shown in Table 1. The small difference in ingredient usage among the 3 replicates was due to the slight variation in the RFCC fat content among replicates. Furthermore, the variation in the RFCC composition was caused by compositional differences among the 3 original FFCC and the amount of fat removed during the fat-removal process. The $\mathrm{pH}$ of LFCC mix was greatly influenced by the amount of MCC and RFCC used in the formula. The buffering capacity of the $\mathrm{MCC}$ resisted $\mathrm{pH}$ change when RFCC was added. The $\mathrm{pH}$ of LFCC mix (before the addition of lactic acid) was 5.86, 5.70, and 5.77 for replicate 1,2 , and 3 , respectively (Table 1 ).
The replicate 1 formula had the lowest amount of RFCC and highest MCC, which explained its high $\mathrm{pH}$ before $\mathrm{pH}$ adjustment relative to replicate 2 and 3. Meanwhile, replicate 2 had higher usage of RFCC, lower usage of MCC, and the RFCC in replicate 2 was more acidic compared with RFCC in replicate 1 , as a result, the $\mathrm{pH}$ of the LFCC mix before $\mathrm{pH}$ adjustment in replicate 2 was lower. Lactic acid was added to the LFCC mixes until a $\mathrm{pH}$ of 5.3 was achieved. The LFCC in replicate 1 required more added lactic acid because it had the highest $\mathrm{pH}$ before the $\mathrm{pH}$ adjustment, whereas LFCC replicate 2 needed the least added lactic acid because it had the lowest initial $\mathrm{pH}$ before the $\mathrm{pH}$ adjustment. The $\mathrm{pH}$ of LFCC after the $\mathrm{pH}$ adjustment were $5.25,5.28$, and 5.28 for replicate 1,2 , and 3 , respectively (Table 1). When all the cheese samples were analyzed for $\mathrm{pH}$ and the rest of compositional analyses after $2 \mathrm{wk}$ in storage, the $\mathrm{pH}$ of LFCC had increased for all 3 replicates to a mean $\mathrm{pH}$ of 5.49 (Table 1). The increase in $\mathrm{pH}$ during $2 \mathrm{wk}$ of refrigerated storage was presumably caused by the buffering action of the minerals from the MCC that gradually became soluble in the water phase of the low- fat cheese during $2 \mathrm{wk}$ of storage at $4^{\circ} \mathrm{C}$. Upreti and Metzger (2007) observed an increase in $\mathrm{pH}$ between $\mathrm{d} 1$ and 14 of full-fat Cheddar cheese made with different levels $\mathrm{Ca}$ and $\mathrm{P}$, residual lactose, and percentage of salt in the moisture. They attributed the increase in $\mathrm{pH}$ to the gradual solubilization of $\mathrm{Ca}$ and $\mathrm{P}$ entrapped by the cheese paracasein network. A delay in the solubilization of entrapped $\mathrm{Ca}$ and $\mathrm{P}$ was also observed, due to restricted mobility and its slow equilibrium (Upreti and Metzger, 2007). Because of this gradual shift in $\mathrm{pH}$ in our LFCC, the production of LFCC in the future (using the approach described in the present study) needs to target a $\mathrm{pH}$ lower than 5.3 at the time of processing, so that the $\mathrm{pH}$ of the final product would be approximately at 5.3 during refrigerated storage.

Lowering the $\mathrm{pH}$ of the LFCC mix during processing to 5.3 served different purposes. First, from a sensory perspective, it improved the perception of acid taste. Second, it helped soften the LFCC protein matrix by releasing the bound calcium from the MCC and this may have caused the shift in bound mineral from the MCC into the water phase, producing the previously mentioned increase in $\mathrm{pH}$ during the first $2 \mathrm{wk}$. Hydrated MCC (approximately 27\% protein) was a colloidal suspension of $\mathrm{CN}$ micelles in water. When preshredded RFCC was added to the hydrated MCC mixture, the particles of RFCC were dispersed in a continuous phase of hydrated MCC by mixing. The addition of rennet acted on the $\kappa-\mathrm{CN}$ in the continuous phase of the hydrated MCC to create a continuous gel matrix with particulate RFCC imbedded in the matrix. When 
LFCC produced by this method is viewed in the context of a filled-gel structure model, the matrix of the LFCC consisted of a protein network of RFCC embedded in a CN network of the renneted MCC. Based on observations in the present study (data not reported), the LFCC without the addition of rennet had short and crumbly texture, owing to minimal interaction of among CN micelles.

\section{Cheese Composition}

Comparison Among Commercial FFCC, $50 \%$ $\boldsymbol{R F C C ,} \mathbf{7 5 \%} \boldsymbol{R F C C}$. The mean cheese composition is reported in Table 2. As the Cheddar cheese fat content was reduced using a conventional Cheddar cheese-making approach for the commercial RFCC, the moisture and protein content of the cheese (Table $2)$ increased $(P<0.05)$. An increase in moisture and protein percentage was expected because of the absence of fat. With increased moisture and lower amount of fat, both 50\% RFCC and 75\% RFCC had lower fat in the dry matter (FDM) than FFCC. The protein in the dry matter (PDM) in 50\% RFCC and $75 \%$ RFCC was higher than FFCC. No difference was detected $(P>0.05)$ in $\mathrm{pH}$, TA, and salt among FFCC, $50 \%$ RFCC, and $75 \%$ RFCC. Given the higher moisture content of the $50 \%$ RFCC and $75 \%$ RFCC compared with FFCC and no salt difference, the percentage salt in the moisture $(\mathbf{S} / \mathbf{M})$ in $50 \%$ RFCC $(3.69 \%)$ and $75 \%$ RFCC $(3.35 \%)$ were lower $(P<0.05)$ than in FFCC $(4.97 \%)$. If $\mathrm{S} / \mathrm{M}$ was to be kept the same, then extra salt addition would have been needed, and that might not be desirable from sensory and nutritional perspective. Mistry and Kasperson (1998) studied the effect of $\mathrm{S} / \mathrm{M}(2.7,3.7,4.5 \% \mathrm{~S} / \mathrm{M})$ on the quality of RFCC (about $50 \%$ reduced fat) made with the conventional cheese-making process and ripened for $24 \mathrm{wk}$. Low-S/M RFCC scored higher on flavor intensity and had better body and texture than high-S/M RFCC. However, the bitter flavor increased in low-S/M RFCC with the concomitant increase in proteolysis. Thus, production of low-S/M RFCC by conventional cheese-making technology used by Mistry and Kasperson (1998) needs to be coupled with the addition of cultures containing peptidase activity to hydrolyze hydrophobic peptides that are associated with bitterness (El Abboudi et al., 1992; Sridhar et al., 2005).

The moisture in the nonfat substance (MNFS) in the $50 \% \mathrm{RFCC}$ and $75 \% \mathrm{RFCC}$ were higher $(P<0.05)$ than the FFCC in our study (Table 2). A decrease in MNFS has been reported in several studies as fat was reduced in cheese (Bryant et al., 1995; Fenelon et al., 2000a; Guinee et al., 2000). This means that the commercial RFCC used in our study retained more moisture in the curd, probably due to a modification in traditional cheese making, than the RFCC made in previously mentioned research studies. The MNFS has been used by cheese makers as an important indicator of the likely flavor and body development in mature, full-fat cheeses (Pearce, 1978). Lawrence and Gilles (1980) reported that full-fat Cheddar cheese with an MNFS higher than $56 \%$ has a marked tendency develop defects during maturation. The 50\% RFCC and $75 \%$ RFCC had an MNFS higher than 56\%; however, no previous studies

Table 2. Mean $(\mathrm{n}=3$ ) chemical composition of full-fat Cheddar cheese (FFCC), reduced-fat Cheddar cheeses (RFCC), and low-fat Cheddar cheese (LFCC)

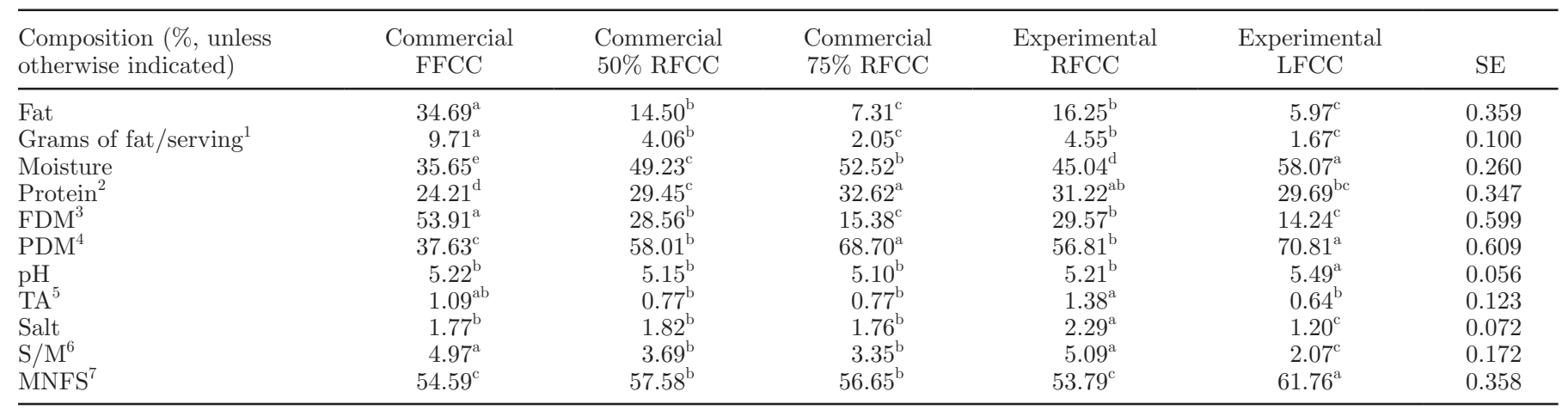

\footnotetext{
${ }^{\mathrm{a}-\mathrm{e}}$ Means in the same row not sharing a common superscript are different $(P<0.05)$.

${ }^{1}$ One serving of cheese $=28 \mathrm{~g}$.

${ }^{2}$ Total nitrogen $\times 6.38$.

${ }^{3} \mathrm{FDM}=$ fat in DM.

${ }^{4} \mathrm{PDM}=$ protein in DM.

${ }^{5} \mathrm{TA}=$ titratable acidity.

${ }^{6} \mathrm{~S} / \mathrm{M}=$ (salt/moisture) $\times 100$.

${ }^{7} \mathrm{MNFS}=$ moisture in nonfat substance.
} 
have reported how higher MNFS affects the quality of lower fat Cheddar cheese during aging. Emmons et al. (1980) suggested that MNFS in low-fat Cheddar cheese needed to be higher than in the full-fat counterpart to achieve a texture closer to the full-fat counterpart, however the effect of higher MNFS on the flavor of low-fat Cheddar cheese was not discussed.

Comparison Among RFCC (50\% RFCC, $75 \%$

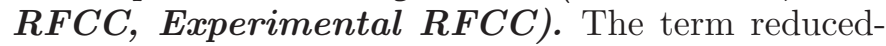
fat is used for a product with at least a $25 \%$ fat reduction compared with its full-fat counterpart (FDADHHS, 2002). In other words, RFCC must not exceed $7.2 \mathrm{~g}$ of fat per serving and can be as low as $1.68 \mathrm{~g}$ of fat per serving, below which the term low-fat can be used. The 50\% RFCC, $75 \%$ RFCC, and experimental RFCC contained $4.06,2.05$, and $4.55 \mathrm{~g}$ of fat per serving, respectively, which qualified them to be labeled reducedfat. Experimental RFCC had lower $(P<0.05)$ moisture than both commercial RFCC. The protein content of the experimental RFCC was higher $(P<0.05)$ than the commercial $50 \%$ RFCC, but no difference in protein content $(P>0.05)$ from the $75 \%$ RFCC was detected (Table 2). If the moisture content of the experimental RFCC was increased to match that of the commercial $50 \%$ RFCC, the percentage of fat, protein, and grams of fat per serving would have been comparable. No difference $(P>0.05)$ was detected in FDM and PDM of $50 \%$ RFCC and experimental RFCC. No difference $(P$ $>0.05)$ in $\mathrm{pH}$ among 3 cheeses was detected. The TA and salt were higher $(P<0.05)$ in experimental RFCC than the 2 commercial RFCC because these compounds were concentrated in the nonfat phase of the cheese during the fat-removal process during production of experimental RFCC. Due to higher salt and lower moisture content, $\mathrm{S} / \mathrm{M}$ of experimental RFCC was higher $(P$ $<0.05)$ than $50 \%$ RFCC and $75 \%$ RFCC. The fat-removal process should not affect MNFS of the resulting RFCC. Thus, MNFS of experimental RFCC was not different $(P>0.05)$ from FFCC, and both the FFCC and experimental RFCC had lower $(P<0.05)$ MNFS than 50\% RFCC and 75\% RFCC. As reported previously (Nelson and Barbano, 2004; Carunchia Whetstine et al., 2006), the experimental RFCC produced by the fat-removal process has a Cheddar flavor intensity comparable to that of full-fat Cheddar

Comparison Between Commercial FFCC and Experimental $\mathbf{L F C C}$. The amount of fat per serving was reduced from $9.71 \mathrm{~g}$ in FFCC to $1.67 \mathrm{~g}$ in LFCC to comply with the FDA regulation for low-fat labeling (Table 2). This was an $83 \%$ reduction of fat from FFCC. Moisture and protein were higher $(P<$ $0.05)$ in LFCC than FFCC, and, as a result, PDM was much higher $(P<0.05)$ in LFCC $(70.81 \%)$ than FFCC $(37.63 \%)$. With lower fat and higher moisture, LFCC had lower $(P<0.05)$ FDM than FFCC. The mean $\mathrm{pH}$ of LFCC (5.49) was higher $(P<0.05)$ than FFCC (5.22). The mean TA of FFCC and LFCC were 1.09 and 0.64 , respectively. No difference $(P>0.05)$ in TA was detected among the 2 cheese types because a large variation in TA (up to $0.4 \%$ difference) was observed among replicates within each sample (individual TA value for each replicate was not reported). The TA of LFCC was lower than expected, given that an average of $0.82 \%$ of racemic lactic acid ( $85 \%$ wt/wt) was added to the LFCC mixture (Table 1). The added lactic acid was a racemic mixture, and it is known the $\mathrm{D}(-)$-lactic acid is less soluble than the $\mathrm{L}(+)$-lactic acid (Dybing et al., 1988; Johnson et al., 1990) in cheese and forms insoluble calcium lactate crystals. This may have created a problem in the recovery of lactic acid in the measurement method for TA of cheese. The method for TA determination in cheese has an initial water extraction step where the cheese is combined with warm RO water to be blended and filtered. An aliquot of the filtrate was then titrated with $0.1 \mathrm{~N} \mathrm{NaOH}$, and the TA was calculated. We suspected that part of the lactic acid that was present in the LFCC was not soluble in warm water and, therefore, didn't pass through the filter, hence it was not quantified.

The LFCC was formulated to have $1.20 \%$ salt in the final product. This low salt target was intentionally done because, at this salt level, we felt that the perception of saltiness was comparable to a regular FFCC. In preliminary trials, an LFCC made at the salt level similar to a regular Cheddar cheese $(1.70 \%$ salt) was perceived to be too salty (data not reported). The mean sodium content of the cheese was calculated to be $195 \mathrm{mg}$ in FFCC and $132 \mathrm{mg}$ in LFCC per each 28 -g serving. The sodium content in LFCC was $32 \%$ lower than FFCC, which would be desirable from the nutritional perspective. The S/M in LFCC (2.07\%) was lower than FFCC (4.97\%). In replacing the fat, the moisture increase was larger than the protein increase in LFCC, which resulted in higher MNFS $(P<0.05)$ in LFCC than FFCC. Both S/M and MNFS are important parameters to assess the potential quality of Cheddar cheese in conventional cheese making. These parameters remain relevant in the LFCC cheese produced by our novel cheese-making process because they would influence the stability of the cheese during its shelf life. The flavor and texture characteristics are achieved at the day of processing. Any undesirable changes in flavor and texture would be the limiting factor of this type of LFCC during its shelf life.

\section{Sensory Analysis}

Texture. The ratio of matrix to filler volume of a cheese gives an insight into the expected cheese texture. 
For commercial Cheddar cheeses with a range of fat contents, the proportion of matrix increased and the filler volume decreased (Table 3) as fat was reduced (Table 2). Limited amounts of cheese prevented formal descriptive profiling of cheese texture. However, in the opinion of 3 experienced cheese judges, the $75 \%$ RFCC was the firmest (lowest filler volume: 67.38\%; Table 3 ) and FFCC was the softest among the commercial cheeses (highest filler volume: $75.79 \%$; Table 3). This observation is consistent with the filled-gel model by Visser (1991) that indicates increasing filler volume makes cheese softer. To maintain a similar filler volume in $50 \%$ RFCC and $75 \%$ RFCC as in FFCC, the amount of moisture would need to be increased to make up for the lower amount of fat. This is technically challenging in a conventional Cheddar cheese making. As an illustration, the commercial $75 \%$ RFCC contained $7.31 \%$ fat (Table 2). To achieve the same filler volume as in commercial FFCC (75.79\%), the moisture in commercial $75 \%$ RFCC needed to be approximately $68.48 \%$, but it was only $52.52 \%$ (Table 2 ).

In comparing commercial FFCC to experimental RFCC and experimental LFCC, the FFCC was expected to be softer because it had a higher filler volume than experimental RFCC and LFCC (Table 3). However, this was not the case. The experimental RFCC contained original cheese matrix (FFCC) that had been disrupted, hence the structural integrity of the matrix was weakened and the texture of the RFCC was softer than the FFCC. The disrupted matrix of the FFCC became the matrix of the experimental RFCC. When the experimental RFCC is dispersed in hydrated MCC to make LFCC, the experimental RFCC becomes an inclusion in the continuous gel matrix formed by the action of rennet on the $\mathrm{CN}$ in the MCC (i.e., primary matrix of LFCC). Does the RFCC contribute to matrix of the LFCC, or does it act as filler? For the experimental LFCC, the percentage matrix reported in Table 3 is the total of all the protein from 2 different sources (i.e., 29.75): MCC and experimental RFCC. One can argue that the effective matrix in experimental LFCC is solely from the protein in MCC, which is calculated to be $18.46 \%$. In this case, the filler volume of the experimental LFCC would be $81.54 \%$, not $70.31 \%$ as reported in Table 3, and the filler volume of the commercial FFCC was $75.79 \%$. The observation by the 3 experienced judges that experimental LFCC was much softer than commercial FFCC (Table 3) is consistent with the idea that the protein in the RFCC ingredient is not acting as matrix in the LFCC.

A typical FFCC contains large fat inclusions due to the mechanical action during cheese making that ruptures milk fat globules and causes fat to coalesce (Rogers et al., 2010). The fat-removal process (Nelson and Barbano, 2004) to produce RFCC from FFCC melts these large fat inclusions, which are then separated and decanted. What was left in the cheese residue (experimental RFCC) were the smaller original fat globules (about $1 \mu \mathrm{m}$ ) entrapped in the matrix. When the experimental RFCC was used as an ingredient for LFCC in this study, the concentration of these small fat globules was further diluted in a continuous phase of hydrated MCC. In comparison, the conventional process of making RFCC used skim milk plus cream, which naturally contains normal size fat globules (ca. $1-4.5 \mu \mathrm{m})$. More original large milk fat globules from the cream were apparent throughout the structure of commercial $75 \%$ RFCC (Figure 1a), whereas the experimental LFCC (Figure 1b) contained only smaller original milk fat globules, even though the total fat contents of the commercial $75 \%$ RFCC and experimental LFCC were almost the same (Table 2). At higher magnification $(100,000 \times)$ scanning electron microscope images, the size of water pockets in experimental LFCC (Figure 1d) appeared larger than in commercial $75 \%$ RFCC (Figure 1c). This agrees with the composition data, which shows higher moisture in experimental LFCC $(58.07 \%)$ than commercial $75 \%$ RFCC (52.52\%). The difference in fat dispersion and size of water pockets in the cheese structure contributed to the difference in perceived texture between commercial $75 \%$ RFCC and experimental LFCC.

To our knowledge, previous attempts to make LFCC have always resulted in much firmer texture than

Table 3. Matrix and filler composition of full-fat Cheddar cheese (FFCC), reduced-fat Cheddar cheeses (RFCC), and low-fat Cheddar cheese (LFCC) based on a filled gel model by Visser (1991)

\begin{tabular}{|c|c|c|c|c|c|}
\hline Item (\%) & $\begin{array}{l}\text { Commercial } \\
\text { FFCC }\end{array}$ & $\begin{array}{l}\text { Commercial } \\
50 \% \text { RFCC }\end{array}$ & $\begin{array}{l}\text { Commercial } \\
75 \% \text { RFCC }\end{array}$ & $\begin{array}{c}\text { Experimental } \\
\text { RFCC }\end{array}$ & $\begin{array}{l}\text { Experimental } \\
\text { LFCC }\end{array}$ \\
\hline Matrix $^{1}$ & $24.21^{\mathrm{d}}$ & $29.45^{\mathrm{c}}$ & $32.62^{\mathrm{a}}$ & $31.22^{\mathrm{ab}}$ & $29.69^{\mathrm{bc}}$ \\
\hline Filler $^{2}$ & 75.79 & 70.55 & 67.38 & 68.78 & 70.31 \\
\hline Observed firmness & Medium & Harder & Hardest & Soft & Softest \\
\hline
\end{tabular}



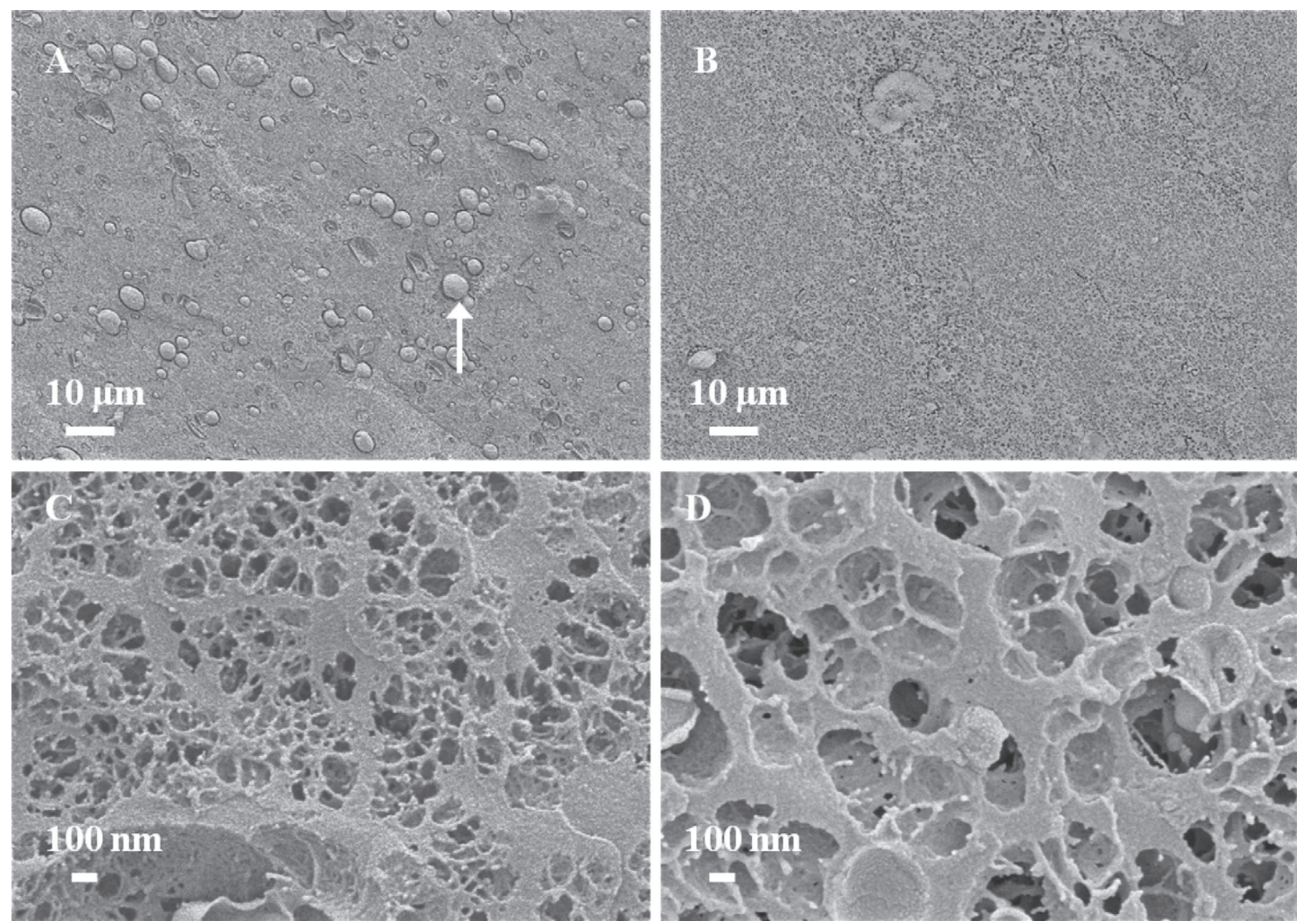

Figure 1. Scanning electron microscopy images of commercial $75 \%$ reduced-fat Cheddar cheese (A and C at 2,000 and $100,000 \times$ magnification, respectively) and experimental low-fat Cheddar (B and D at 2,000 and 100,000× magnification, respectively). The white arrow in A indicates visible fat globules. The protein matrix appears as a lace-like structure at higher magnification (C, D).

FFCC, which contributes to low consumer acceptability of LFCC (Childs and Drake, 2009). The technology demonstrated in the current study represents a different approach to produce LFCC and the demonstration that modification of the cheese matrix structure can produce LFCC with soft texture. A more formal and complete descriptive sensory and instrument analysis of the texture of LFCC produced by this new approach needs to be conducted.

Flavor. From the PCA biplot (Figure 2), we determined which flavor attributes strongly characterized each cheese type. The PCA plot also provided a view of how different or similar cheese types were based on the flavor attributes. About $61 \%$ variation among the cheese types can be explained by attributes closer to the $\mathrm{PC} 1$ axis (horizontal), and the other $31 \%$ can be explained by attributes closer to the $\mathrm{PC} 2$ axis (vertical). This means that the attributes closer to PC1 axis were the major flavor attributes that distinguished different cheese types. The FFCC had different flavor attributes than other cheeses; FFCC was characterized by attributes (such as nutty, fruity, milkfat, catty, brothy, sweet, and sulfur) close to the positive loading of PC1 axis (typical aged Cheddar character), whereas other cheeses were lacking of these attributes. Both 50\% RFCC and $75 \%$ RFCC lay between the negative loading on $\mathrm{PC} 1$ and positive loading of $\mathrm{PC} 2$ axes, which was characterized by whey and cooked flavor. The LFCC had a distinct flavor character that was different from the rest of the cheeses that was positioned between the negative loading of the PC1 and PC2 axes, which was characterized by bitter and grapey-tortilla flavors.

The mean descriptive flavor scores from the descriptive sensory analysis are reported in Table 4. Brothy flavor is a common attribute of full-fat Cheddar cheese that is $>3$ mo old (Drake et al., 2001, 2008a,b) and 
Biplot (axes PC1 and PC2: $92.65 \%$ )

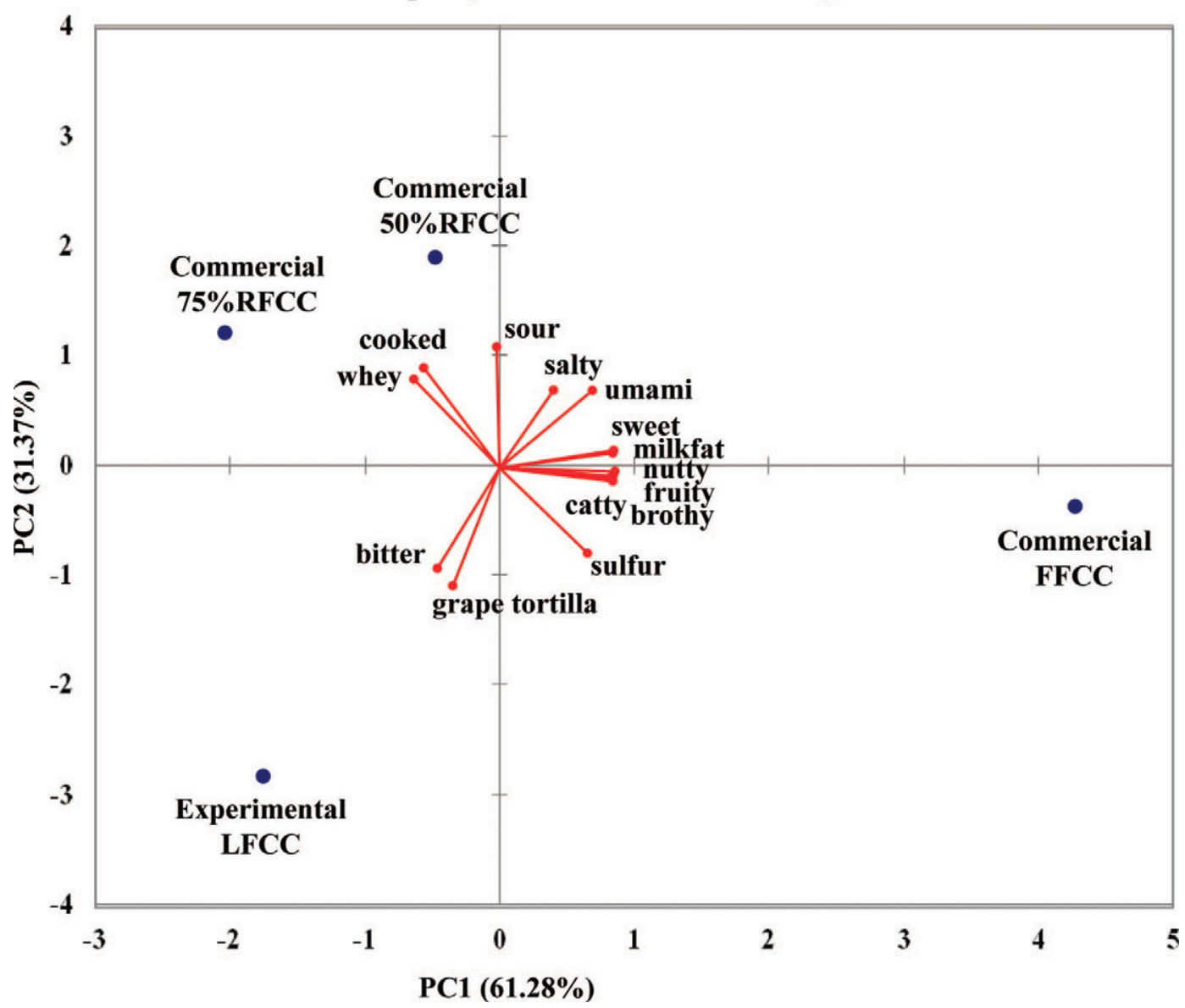

Figure 2. Principal component (1 and 2) biplot of descriptive analysis of Cheddar cheese samples with various fat content. RFCC $=$ reducedfat Cheddar cheese; LFCC = low-fat Cheddar cheese; FFCC $=$ full-fat Cheddar cheese. Color version available in the online PDF.

when not balanced with other flavors, has also been reported as a flavor defect in lower fat Cheddar cheese (Milo and Reineccius, 1997; Drake et al., 2010). However, all of the lower-fat Cheddar cheeses exhibited less of this flavor than the FFCC. No difference $(P>0.05)$ in saltiness was detected among the different types of cheeses, despite the fact that LFCC was $32 \%$ lower in sodium than FFCC. The high moisture content of the LFCC might facilitate a faster release of this watersoluble compound, hence the saltiness of LFCC was perceived to be similar to FFCC. The FFCC had the highest sulfur flavor among the cheese types. Low sulfur flavor in 50\% RFCC and $75 \%$ RFCC was expected because previous studies (Dimos et al., 1996; Drake et al., 2010) had also demonstrated reduced sulfur compounds and sulfur flavor in conventionally produced, lower fat Cheddar cheese. Surprisingly, experimental LFCC had significantly higher sulfur flavor $(P<0.05)$ than commercial 50\% RFCC and $75 \%$ RFCC. The sulfur flavor in LFCC was derived from experimental
RFCC, which retained the Cheddar flavor of the FFCC it was made from (Carunchia Whetstine et al. 2006). Grapey-tortilla is not a common descriptor for Cheddar cheese, and it has not been reported in previous studies. This flavor was detected in LFCC, but not in other Cheddar cheeses. The grapey-tortilla flavor came from the dried MCC. Fresh liquid MCC does not have this flavor, but this flavor has been reported in spray-dried milk protein concentrates (Drake et al., 2009).

The FFCC had higher $(P<0.05)$ milk fat flavor than other cheeses. Lactones contribute to milk fat flavor (Drake et al., 2001). Milk with lower fat content had lower lactone concentration, and less lactone precursors were observed in the cheese (Drake et al., 2010), which explained the lower milk fat flavor in lower-fat cheeses. Although milk fat is required for the production of lactones (Wijesundera and Watkins, 2000), the removal of fat from an aged FFCC does not alter the milk fat flavor intensity because lactones reside in the aqueous phase of the cheese (Carunchia Whetstine et al. 2006). 
Table 4. The mean sensory attribute flavor scores from descriptive sensory analysis ${ }^{1}$ of full-fat Cheddar cheese (FFCC), reduced-fat Cheddar cheeses (RFCC), and low-fat Cheddar cheese (LFCC)

\begin{tabular}{lccccc}
\hline Attribute & $\begin{array}{c}\text { Commercial } \\
\text { FFCC }\end{array}$ & $\begin{array}{c}\text { Commercial } \\
50 \% \text { RFCC }\end{array}$ & $\begin{array}{c}\text { Commercial } \\
75 \% \text { RFCC }\end{array}$ & $\begin{array}{c}\text { Experimental } \\
\text { LFCC }\end{array}$ & SE \\
\hline Cooked & $2.62^{\mathrm{b}}$ & $3.32^{\mathrm{a}}$ & $3.40^{\mathrm{a}}$ & $2.79^{\mathrm{b}}$ & 0.057 \\
Whey & $1.51^{\mathrm{c}}$ & $2.53^{\mathrm{a}}$ & $2.70^{\mathrm{a}}$ & $1.90^{\mathrm{b}}$ & 0.063 \\
Diacetyl & $\mathrm{ND}^{2}$ & $\mathrm{ND}$ & $\mathrm{ND}$ & ND & NA $^{3}$ \\
Milkfat & $3.50^{\mathrm{a}}$ & $2.20^{\mathrm{b}}$ & $1.15^{\mathrm{d}}$ & $1.30^{\mathrm{c}}$ & 0.049 \\
Fruity & $0.51^{\mathrm{a}}$ & $\mathrm{ND}$ & $\mathrm{ND}$ & $\mathrm{ND}$ & 0.038 \\
Brothy & $2.98^{\mathrm{a}}$ & $2.15^{\mathrm{b}}$ & $2.26^{\mathrm{b}}$ & $2.16^{\mathrm{b}}$ & 0.056 \\
Sulfur & $3.17^{\mathrm{a}}$ & $1.88^{\mathrm{c}}$ & $1.56^{\mathrm{d}}$ & $2.63^{\mathrm{b}}$ & 0.053 \\
FFA & $\mathrm{ND}$ & $\mathrm{ND}$ & $\mathrm{ND}$ & $\mathrm{ND}$ & NA \\
Grapey-tortilla & $\mathrm{ND}$ & $\mathrm{ND}$ & $\mathrm{ND}$ & $2.95^{\mathrm{a}}$ & 0.025 \\
Nutty & $1.11^{\mathrm{a}}$ & $\mathrm{ND}$ & $\mathrm{ND}$ & $\mathrm{ND}$ & 0.053 \\
Catty & $1.18^{\mathrm{a}}$ & $\mathrm{ND}$ & $\mathrm{ND}$ & $\mathrm{ND}$ & NA \\
Sweet & $2.60^{\mathrm{a}}$ & $2.10^{\mathrm{b}}$ & $1.78^{\mathrm{c}}$ & $1.78^{\mathrm{c}}$ & 0.052 \\
Sour & $3.10^{\mathrm{b}}$ & $3.18^{\mathrm{ab}}$ & $3.29^{\mathrm{a}}$ & $2.87^{\mathrm{c}}$ & 0.047 \\
Salty & $3.55^{\mathrm{a}}$ & $3.95^{\mathrm{a}}$ & $3.01^{\mathrm{a}}$ & $2.97^{\mathrm{a}}$ & 0.306 \\
Umami & $3.09^{\mathrm{a}}$ & $2.80^{\mathrm{b}}$ & $2.67^{\mathrm{b}}$ & $2.24^{\mathrm{c}}$ & 0.048 \\
Bitter & $\mathrm{ND}$ & $\mathrm{ND}$ & $0.61^{\mathrm{b}}$ & $0.85^{\mathrm{b}}$ & 0.064 \\
\hline
\end{tabular}

${ }^{\mathrm{a}-\mathrm{d}}$ Means in the same row not sharing a common superscript are different $(P<0.05)$.

${ }^{1}$ Scores were based on the 15 -point universal intensity spectrum scale where $0=$ not detected and $15=$ very high (Meilgaard et al., 1999; Drake et al., 2001).

${ }^{2} \mathrm{ND}=$ not detected.

${ }^{3} \mathrm{NA}=$ not applicable.

Furthermore, lactones have lower sensory threshold level in water than in oil (Leksrisompong et al., 2010). Lower milk fat flavor in experimental LFCC might be attributed to the fact that two-thirds of the ingredients used to make LFCC (e.g., MCC, water, salt, lactic acid) did not contain lactones, and these ingredients reduced the flavor contribution of lactones from RFCC, which only accounted for one-third of the ingredients to make LFCC (Table 1). It was also possible that lactones were bound to protein in the MCC. Flavorants bound to protein will not contribute to taste and aroma if they are not released during mastication (Plug and Haring, 1993; Damodaran, 2008). Catty and slight fruity flavors were detected in FFCC but not in other cheeses. Nutty flavor was detected only in FFCC and in 50\% RFCC at a lower level. The catty, fruity, and nutty flavors have been reported previously as typical attributes of aged full-fat Cheddar cheese (Urbach, 1997; Drake et al., 2001). From a previous study on RFCC made by the fat-removal process (Carunchia Whetstine et al. 2006), the flavor compounds for catty, fruity, and nutty flavors were soluble in the fat fraction of the cheese, hence the resulting RFCC had less intensity of these flavors.

In the current study, RFCC only contributed onethird of the total ingredients to make the LFCC. This explains why these flavors were no longer detectable in LFCC. The LFCC in the current study was perceived to have more bitterness than other cheeses, but even so, LFCC had a bitter score $<1$ on a 15 -point scale. A comprehensive sensory analysis of Cheddar cheeses from around the world had a broad range of bitterness in Cheddar cheese from a score of 0 (not detectable) to 3.0 (Drake et al., 2001). Thus, it is reasonable to state that all the cheese samples in the current study were relatively low in bitterness. Cooked and whey flavor was higher in 50\% RFCC and 75\% RFCC than in FFCC and LFCC. In the production of 50\% RFCC and $75 \%$ RFCC, more moisture was retained in the curd (less whey was expelled) than in FFCC. This may account for higher whey flavor in the commercial RFCC than FFCC. In comparison, MCC used as a major ingredient to produce LFCC contained very little whey protein and lactose. The LFCC had a lower sourness intensity score $(P<0.05)$ than other cheeses. The umami and sweet flavor was higher in FFCC than other cheeses. Diacetyl and FFA flavors were not detected in any of the cheeses.

In comparison to commercial RFCC, LFCC contained some flavor and, particularly, texture attributes that were similar to FFCC. Nonetheless, the flavor of LFCC still needs improvement to make it comparable to FFCC. This includes increasing sourness, umami, sweet, milkfat, brothy, nutty, fruity, and catty flavors, and reducing bitter and grapey-tortilla flavor. A possible improvement strategy would be to incorporate a flavoring ingredient that can enhance the missing flavors and at the same time mask undesirable flavors. Enzyme-modified cheese is an example of flavor ingredients that can be added to the formula to serve these roles. A preliminary experiment (data not reported) with enzyme-modified cheese addition did show masking of the grapey-tortilla flavor. 


\section{Possible New Industrial Process}

A 50\% RFCC can be made from FFCC that is produced by the fat-removal process (Nelson and Barbano, 2004). The FFCC could be from trim from a cut-and wrap Cheddar cheese packaging plant. For a continuous industrial process, we envision that FFCC would be shredded and placed on a running belt passing through a heat tunnel. The warm shredded cheese would be fed into a continuous horizontal decanter centrifuge (Figure 15.8 in Anonymous, 2003) to separate the liquid milk fat from RFCC. Meanwhile in a separate unit process, MCC powder would be hydrated in a cooker $\left(60^{\circ} \mathrm{C}\right)$ with continuous mixing. The RFCC, salt, and lactic acid would be added to the hydrated MCC mixture while maintaining the heating and mixing until uniform. The LFCC mix would be cooled to 35 to $38^{\circ} \mathrm{C}$ and rennet added, followed by immediate mixing. The final LFCC mix would be injected into a mold to achieve a rectangular shape and allow for a small volume of whey drainage over a period of $30 \mathrm{~min}$. The LFCC then would be removed from the mold and packaged. The packaged LFCC would be maintained at ambient temperature $\left(21^{\circ} \mathrm{C}\right)$ for $30 \mathrm{~min}$ to allow the structure become uniform and closed. The LFCC would be cooled and stored at $4^{\circ} \mathrm{C}$.

In our study, we did not investigate whether the small amount of whey produced (1.82\% of the total cheese) after the addition of rennet would be reabsorbed into the cheese if the cheese was packaged immediately and cooled from 38 to $4^{\circ} \mathrm{C}$. Olabi and Barbano (2002) demonstrated temperature-induced moisture migration within $290 \mathrm{~kg}$ of cheese blocks using a laboratory-scale apparatus that stimulated the temperature gradient that developed during cooling of a cheese block (Reinbold and Ernstrom, 1988; Reinbold et al., 1992; Barbano, 2001). As the cheese began to cool from the surface of the cheese, hydrophobic interactions between proteins on the surface of the cheese are weakened, and the protein-water interaction becomes favored. As a result, moisture migrates from the higher temperature region (in the center of the cheese) to the lower temperature region (on the surface of the cheese). If the whey produced in our LFCC making can be reabsorbed back into the cheese by the protein-water interaction induced by cooling, the whey draining step (after depositing the cheese into a mold) might be eliminated, and the LFCC would be packaged right away after being shaped and removed from the mold. The LFCC made using this novel process could be marketed directly without aging. Flavor could be enhanced by addition of a flavoring ingredient such as enzyme-modified cheese. The absence of an aging process for the LFCC translates to significant cost savings because the production of low- fat cheese could be done in response to orders to meet fluctuating market demand without aging.

\section{CONCLUSIONS}

A new approach to produce LFCC was developed by combining $50 \%$ RFCC made using the fat-removal process of Nelson and Barbano (2004) with hydrated MCC, lactic acid, rennet, and salt. The LFCC made by this process complies with the FDA low-fat label requirements. The LFCC had $83 \%$ less fat, $32 \%$ less sodium, higher protein, and moisture than FFCC. When the cheese texture was evaluated in the context of a filled-gel model consisting of matrix and filler (100\% minus percentage of matrix), the LFCC had lower filler volume than FFCC but the LFCC had a softer texture than FFCC. The LFCC contained some of the original FFCC cheese matrix that had been disrupted by the fat-removal process, and this original FFCC matrix was embedded in a new LFCC matrix formed by the action of rennet on $\mathrm{CN}$ from the continuous phase of hydrated MCC. Thus, the texture of the LFCC was softer than the FFCC it was made from, whereas commercial $50 \%$ RFCC and $75 \%$ RFCC were firmer than the FFCC. The sulfur flavor in LFCC was closer to FFCC than the commercial 50\% RFCC and 75\% RFCC. The LFCC had bitter and grape-tortilla off-flavors that came from the dried MCC ingredient. The commercial RFCC and LFCC made in this study were missing the typical aged Cheddar character (catty, nutty, fruity, brothy, milk fat) found in FFCC. Future work to improve the flavor of LFCC made by the process described in this study should include the addition of a flavoring ingredient (e.g., enzyme-modified cheese) to enhance the aged Cheddar flavors and mask undesirable flavors.

\section{ACKNOWLEDGMENTS}

The authors thank the Northeast Dairy Foods Research Center and the New York State Milk Promotion Board (Albany, NY) for partial funding of this research. The technical assistance of Michael Adams, Michelle Bilotta, Sara Bova, Maureen Chapman, Chassidy Coon, Emily Hurt, Jessica Mallozzi, Mark Newbold, Justyna Zulewska from the Department of Food Science at Cornell University, the staff of the Cornell Dairy Plant, and the Dairy Research Institute Sensory Applications Laboratory at North Carolina State University was greatly appreciated.

\section{REFERENCES}

Andersen, L. T., Y. Ardo, and W. L. P. Bredie. 2010. Study of tasteactive compounds in the water-soluble extract of mature Cheddar cheese. Int. Dairy J. 20:528-536. 
Anonymous. 2003. Whey Processing. Page 355 in Dairy Processing Handbook. Tetra Pak, Lund, Sweden.

AOAC International. 2000. Official Methods of Analysis. 17th ed. AOAC International, Gaithersburg, MD.

Aston, J. W., and L. K. Creamer. 1986. Contribution of the components of the water-soluble fraction to the flavour of Cheddar cheese. N.Z. J. Dairy Sci. Tech. 21:229-248.

Banks, J. M. 2004. The technology of low-fat cheese manufacture. Int. J. Dairy Technol. 57:199-207.

Banks, J. M., E. Y. Brechany, and W. W. Christie. 1989. The production of low fat Cheddar-type cheese. J. Soc. Dairy Technol. 42:6-9.

Barbano, D. M. 2001. Moisture nonuniformity and sampling errors in large Cheddar cheese blocks. J. AOAC Int. 84:613-619.

Bryant, A., Z. Ustunol, and J. Steffe. 1995. Texture of Cheddar cheese as influenced by fat reduction. J. Food Sci. 60:1216-1219.

Carunchia Whetstine, M. E., M. A. Drake, B. K. Nelson, and D. M. Barbano. 2006. Flavor profiles of full-fat and reduced-fat cheese and cheese fat made from aged Cheddar with the fat removed using a novel process. J. Dairy Sci. 89:505-517.

Childs, J. L., and M. Drake. 2009. Consumer perception of fat reduction in cheese. J. Sens. Stud. 24:902-921.

Dabour, N., E. Kheadr, N. Benhamou, I. Fliss, and G. LaPointe. 2006. Improvement of texture and structure of reduced-fat Cheddar cheese by exopolysaccharide-producing lactococci. J. Dairy Sci. 89:95-110.

Damodaran, S. 2008. Amino acids, peptides, and proteins. Pages 282 283 in Food Chemistry. S. Damodaran, K. L. Parkin, and O. R. Fennema, ed. CRC Press, Boca Raton, FL.

Dimos, A., G. E. Urbach, and A. J. Miller. 1996. Changes in flavour and volatiles of full-fat and reduced-fat Cheddar cheeses during maturation. Int. Dairy J. 6:981-995.

Drake, S. L., P. D. Gerard, and M. A. Drake. 2008a. Consumer preferences for mild Cheddar cheese flavor. J. Food Sci. 73:S449-S455.

Drake, M. A., S. McIngvale, P. Gerard, K. R. Cadwallader, and G. V. Civille. 2001. Development of a descriptive language for Cheddar cheese. J. Food Sci. 66:1422-1427.

Drake, M. A., R. E. Miracle, and D. J. McMahon. 2010. Impact of fat reduction on flavor and flavor chemistry of Cheddar cheeses. J. Dairy Sci. 93:5069-5081.

Drake, M. A., R. E. Miracle, and J. M. Wright. 2009. Sensory properties of dairy proteins. Pages 429-448 in Milk Proteins: From Expression to Food. A. Thompson, M. Boland, and H. Singh, ed. Elsevier, Amsterdam, the Netherlands.

Drake, M. A., and B. G. Swanson. 1995. Reduced- and low-fat cheese technology: A review. Trends Food Sci. Technol. 6:366-369.

Drake, M. A., M. D. Yates, and P. D. Gerard. 2008b. Determination of regional differences in flavor for U.S. Cheddar cheeses aged for 6 months or longer. J. Food Sci. 73:S199-S208.

Dybing, S. T., J. A. Wiegand, S. A. Brudvig, E. A. Huang, and R. C. Chandan. 1988. Effect of processing variables on the formation of calcium lactate crystals on Cheddar cheese. J. Dairy Sci. 71:1701-1710.

El-Abboudi, M., M. El-Soda, S. Pandian, M. Barreau, G. Trepanier, and R. E. Simard. 1992. Peptidase activities in debittering and nondebittering strains of lactobacilli. Int. Dairy J. 2:55-64.

Emmons, D. B., M. Kalab, E. Larmond, and R. J. Lowrie. 1980. Milk gel structure. X. Texture and microstructure in Cheddar cheese made from whole milk and from homogenized low-fat milk. J. Texture Stud. 11:15-34.

FDA-DHHS. 2002. 21CFR101.62b: Nutrient content claims for fat, fatty acid, and cholesterol content of foods. Food and Drug Administration-Department of Health and Human Services, Washington, DC. Accessed Feb. 20, 2012. http://edocket.access.gpo. gov/cfr_2002/aprqtr/21cfr101.62.htm.

Fenelon, M. A., T. P. Beresford, and T. P. Guinee. 2002. Comparison of different bacterial culture systems for the production of reduced-fat Cheddar cheese. Int. J. Dairy Technol. 55:194-203.

Fenelon, M. A., T. P. Guinee, C. Delahunty, J. Murray, and F. Crowe. 2000b. Composition and sensory attributes of retail Cheddar cheese with different fat contents. J. Food Compost. Anal. 13:13-26.
Fenelon, M. A., P. O'Connor, and T. P. Guinee. 2000a. The effect of fat content on the microbiology and proteolysis in Cheddar cheese during ripening. J. Dairy Sci. 83:2173-2183.

Guinee, T. P., M. A. E. Auty, and M. A. Fenelon. 2000. The effect of fat content on the rheology, microstructure and heat-induced functional characteristics of Cheddar cheese. Int. Dairy J. 10:277-288.

Guinee, T. P., M. A. Fenelon, E. O. Mulholland, B. T. O'Kennedy, N. O'Brien, and W. J. Reville. 1998. The influence of milk pasteurization temperature and $\mathrm{pH}$ at curd milling on the composition, texture and maturation of reduced-fat Cheddar cheese. Int. J. Dairy Technol. 51:1-10.

Johnson, M. E., and C. M. Chen. 1995. Technology of manufacturing reduced-fat Cheddar cheese. Pages 331-337 in Chemistry of Structure-Function Relationships in Cheese. Plenum Press, New York, NY.

Johnson, M. E., R. Kapoor, D. J. McMahon, D. R. McCoy, and R. G. Narasimmon. 2009. Reduction of sodium and fat levels in natural and processed cheeses: Scientific and technological aspects. Compr. Rev. Food Sci. Food Saf. 8:252-268.

Johnson, M. E., B. A. Riesterer, C. Chen, B. Tricomi, and N. F. Olson. 1990. Effect of packaging and storage-conditions on calcium lactate crystallization on the surface of Cheddar cheese. J. Dairy Sci. 73:3033-3041.

Kim, M. K., S. L. Drake, and M. A. Drake. 2011. Evaluation of key flavor compounds in reduced- and full-fat Cheddar cheeses using sensory studies on model systems. J. Sens. Stud. 26:278-290.

Konuklar, G., G. E. Inglett, C. J. Carriere, and F. C. Felker. 2004 Use of a beta-glucan hydrocolloidal suspension in the manufacture of low-fat Cheddar cheese: Manufacture, composition, yield and microstructure. Int. J. Food Sci. Technol. 39:109-119.

Lau, K. Y., D. M. Barbano, and R. R. Rasmussen. 1991. Influence of pasteurization of milk on protein breakdown in Cheddar cheese during aging. J. Dairy Sci. 74:727-740.

Lawrence, R. C., and J. Gilles. 1980. The assessment of the potential quality of young Cheddar cheese. N.Z. J. Dairy Sci. Tech. 15:1-12.

Leksrisompong, P., D. M. Barbano, A. E. Foegeding, P. Gerard, and M. Drake. 2010. The roles of fat and $\mathrm{pH}$ on the detection thresholds and partition coefficients of three compounds: Diacetyl, deltadecalactone and furaneol. J. Sens. Stud. 25:347-370.

Lo, C. G., and E. D. Bastian. 1998. Incorporation of native and denatured whey proteins into cheese curd for manufacture of reduced fat, Havarti-type cheese. J. Dairy Sci. 81:16-24.

McGugan, W. A., D. B. Emmons, and E. Larmond. 1979. Influence of volatile and non-volatile fractions on intensity of Cheddar cheese flavor. J. Dairy Sci. 6:398-403.

Meilgaard, M. M., G. V. Civille, and B. T. Carr. 1999. Selection and training of panel members. Pages 174-176 in Sensory Evaluation Techniques. $3^{\text {rd }}$ ed. CRC Press, Boca Raton, FL.

Milo, C., and G. A. Reineccius. 1997. Identification and quantification of potent odorants in regular fat and low-fat mild Cheddar cheese. J. Agric. Food Chem. 45:3590-3594.

Mistry, V. V. 2001. Low fat cheese technology. Int. Dairy J. 11:413422

Mistry, V. V., and K. M. Kasperson. 1998. Influence of salt on the quality of reduced-fat Cheddar cheese. J. Dairy Sci. 81:1214-1221.

Nelson, B. K., and D. M. Barbano. 2004. Reduced-fat Cheddar cheese manufactured using a novel fat removal process. J. Dairy Sci. $87: 841-853$.

Olabi, A., and D. M. Barbano. 2002. Temperature-induced moisture migration in reduced-fat Cheddar cheese. J. Dairy Sci. 85:21142121.

Pearce, K. N. 1978. The relationship between fat and moisture in cheese. N.Z. J. Dairy Sci. Tech. 13:59-60.

Plug, H., and P. Haring. 1993. The role of ingredient-flavor interactions in the development of free foods. Trends Food Sci. Technol. $4: 150-152$.

Reinbold, R. S., and C. A. Ernstrom. 1988. Effect of nonuniform cooling on moisture, salt, and $\mathrm{pH}$ distribution in 290-kilogram blocks of stirred-curd Cheddar cheese. J. Dairy Sci. 71:1499-1506. 
Reinbold, R. S., C. A. Ernstrom, and C. L. Hansen. 1992. Temperature, $\mathrm{pH}$, and moisture profiles during cooling of 290-kilogram stirred-curd Cheddar cheese blocks. J. Dairy Sci. 75:2071-2082.

Rogers, N. R., D. J. McMahon, C. R. Daubert, T. K. Berry, and E. A. Foegeding. 2010. Rheological properties and microstructure of Cheddar cheese made with different fat contents. J. Dairy Sci. 93:4565-4576.

Schepers, A. 2005. More choices, better flavor for health-conscious cheese lovers. Environ. Nutr. 28:5.

Sridhar, V. R., J. E. Hughes, D. L. Welker, J. R. Broadbent, and J. L. Steele. 2005. Identification of endopeptidase genes from the genomic sequence of Lactobacillus helveticus CNRZ32 and the role of these genes in hydrolysis of model bitter peptides. Appl. Environ. Microbiol. 71:3025-3032.

Upreti, P., and L. E. Metzger. 2007. Influence of calcium and phosphorus, lactose, and salt-to-moisture ratio on Cheddar cheese quality: pH changes during ripening. J. Dairy Sci. 90:1-12.

Urbach, G. 1997. The chemical and biochemical basis of cheese and milk aroma. Pages 253-298 in Microbiology and Biochemistry of
Cheese and Fermented Milk. B. A. Law, ed. Chapman and Hall, London, UK.

USDA CNPP. 2010. Dietary guidelines for Americans. United States Department of Agriculture Center for Nutrition Policy and Promotion. Washington, DC. Accessed Mar. 21, 2012. http://www.cnpp. usda.gov/DGAs2010-PolicyDocument.htm.

Visser, J. 1991. Factors affecting the rheological and fracture properties of hard and semi-hard cheese. Pages 49-61 in Rheological and Fracture Properties of Cheese. P. Walstra, ed. International Dairy Federation, Brussels, Belgium.

Wehr, M. H., and J. F. Frank, eds. 2004. Standard Methods for the Examination of Dairy Products. 17th ed. Am. Publ. Health Assoc. Inc., Washington, DC.

Wijesundera, C., and P. Watkins. 2000. Milkfat essential for the development of Cheddar cheese flavour. Aust. J. Dairy Technol. 55:86 